\title{
Lipopolysaccharide-treated Human Monocytes Regulate Gene Expressions After Interactions with Human Adipocytes
}

\author{
Teruko Honda*1 and Hiroyuki Inagawa ${ }^{2,3}$ \\ ${ }^{1}$ Department of Medical Technology, School of Life and Environmental Science, Azabu University, Japan \\ ${ }^{2}$ Research Institute for Healthy Living, Niigata University of Pharmacy and Applied Life Sciences, Japan \\ ${ }^{3}$ Control of Innate Immunity Technology Research Association, Department of Research and Development, Japan
}

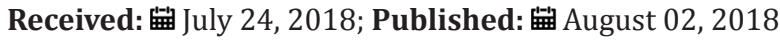

*Corresponding author: Teruko Honda, Department of Medical Technology, School of Life and Environmental Science, Azabu University, Kanagawa, Japan

\begin{abstract}
Introduction: Monocytes infiltrate tissues and differentiate into tissue-specific macrophages by interaction with other cells in tissues. Macrophages in the arterial wall uptake of oxidized LDL and form foam cells and induce inflammatory changes in tissues by secreting inflammatory cytokines. Chronic inflammation is believed to be involved in the development of cancer and lifestyle-related diseases. Whereas, in human monocytes, the mRNA expression of inflammatory factors increases by interactions with cancer cells, however, this increase can be suppressed by pretreatment with low-dose LPS. In the present study, we investigated changes in the gene expression of some key cytokines, inflammatory factors [IL-1 $\beta$ and adiponectin] and a chemotactic factor [MCP-1], after interactions between human adipocytes and LPS-pretreated human monocytes.
\end{abstract}

Materials and Methods: The human monocyte cell line THP-1 was treated with LPS and subsequently co-cultured with human adipocytes using an insert co-culture system. The gene expressions of inflammatory factors and chemotactic factor were analyzed using quantitative real-time PCR and DNA microarray.

Results: The increased mRNA expression of $I L-1 \beta$ in human adipocytes after co-culture was suppressed by interaction with LPS-pretreated THP-1 cells. The decreased mRNA expression of adiponectin in human adipocytes after co-culture was increased by interaction with LPS-pretreated THP-1 cells. In addition, the increased mRNA expression of MCP-1 in THP-1 cells after interaction with human adipocytes was suppressed by LPSpretreatment.

Conclusion: LPS-pretreated human monocytes may have anti-inflammatory effect in adipose tissues. LPS-treated human monocytes may be beneficial for the prevention of diseases caused by chronic inflammation.

Keywords: Monocyte, Adipocyte, Co-Culture, Lipopolysaccharide, Inflammatory Factor

Abberevations: LDL: low density lipoprotein; LPS: lipopolysaccharide; IL: interleukin; MCP-1: Monocyte Chemotactic Protein-1; PCR: Polymerase Chain Reaction; VEGF: Vascular Endothelial Growth Factor; TNF: Tumor Necrosis Factor

\section{Introduction}

Monocytes are a type of leukocyte that play an important role in the phagocytosis of pathogenic microorganisms and maintenance of homeostasis. Although monocytes are typically found in the blood, they may infiltrate tissues and differentiate into macrophages [1,2]. It is known that macrophages interact with other cells in tissues and take on tissue-specific functions and morphologies [3]. It has been shown that tumor-associated macrophages infiltrated tumor tissues promote metastasis and invasion of cancer [4-7]. Furthermore, it has been shown that macrophages infiltrated the arterial wall uptake of oxidized LDL and form foam cells [8]. Foamy macrophages in the arterial wall induce inflammatory changes in tissues by secreting inflammatory cytokines [9-11]. In recent years, it has become clear that chronic inflammation is involved in the development of cancer and lifestyle-related diseases such as diabetes, stroke, and arteriosclerosis $[12,13]$. Therefore, macrophages infiltrating tissues may be key cells in the immune response.

LPS is an extracellular membrane component of gram-negative bacteria. When a high concentration of LPS is intravenously administered, it causes severe systemic inflammation and acute 
septic shock [14]. On the other hands, it has been reported that environmental exposure to LPS in childhood might have an important role in the development of tolerance to ubiquitous allergens [15]. Previously, we reported that the mRNA expression of inflammatory factors in human monocytes increased by interactions with cancer cells and that this increase can be suppressed by pretreatment with low-dose LPS [16-18]. These findings suggested that LPS-treated human monocytes regulate inflammatory reactions. Whereas, it has been shown that inflammatory changes observed in adipose tissues with visceral obesity contribute to the development of metabolic syndrome [19-22]. Oral or transdermal administration of LPS has been shown to induce decreases in fasting blood glucose and LDL cholesterol levels [23-25]. LPS treatment on monocytes/ macrophages may change inflammatory reactions in adipose tissues. Here, we investigated changes in the gene expression of inflammatory factors, $I L-1 \beta$ and adiponectin, and chemotactic factor, $M C P-1$, after interactions between human adipocytes and LPS-pretreated human monocytes.

\section{Materials and Methods}

\section{Cells}

THP-1 cells obtained from DS Pharma Biomedical were cultured in a $5 \% \mathrm{CO}_{2}$ atmosphere at $37^{\circ} \mathrm{C}$ in RPMI-1640 medium (WAKO Pure Chemical Industries, Ltd., Osaka, Japan) containing 10\% fetal calf serum supplemented with 100 units/ml each of penicillin and streptomycin (WAKO Pure Chemical Industries, Ltd.). HWP-c cells obtained from PromoCell (PromoCell GmbH, Heidelberg, Germany) were cultured in a $5 \% \mathrm{CO}_{2}$ atmosphere at $37^{\circ} \mathrm{C}$ in Preadipocyte Growth Medium (PromoCell GmbH). After reaching confluency, cells were cultured for $72 \mathrm{~h}$ in Preadipocyte Differentiation Medium (PromoCell GmbH). Next, cells were cultured in Adipocyte Nutrition Medium (PromoCell GmbH) until they matured into adipocytes.

\section{Cell co-culture}

THP-1 cells were treated with ultra-pure Escherichia coli LPS $(100 \mathrm{pg} / \mathrm{ml}, 10 \mathrm{ng} / \mathrm{ml}$, or $1 \mu \mathrm{g} / \mathrm{ml}$ ) (InvivoGen Corporation, San Diego, CA, USA) in a $5 \% \mathrm{CO}_{2}$ atmosphere at $37^{\circ} \mathrm{C}$ for $3 \mathrm{~h}$, washed with PBS (-) (WAKO Pure Chemical Industries, Ltd.), and resuspended in RPMI-1640 medium (WAKO Pure Chemical Industries, Ltd.). THP1 cells and adipocytes were co-cultured in a $5 \% \mathrm{CO}_{2}$ atmosphere at $37^{\circ} \mathrm{C}$ in RPMI-1640 medium (WAKO Pure Chemical Industries, Ltd.) using a cell culture insert with a $0.4 \mu \mathrm{m}$ porous membrane (Becton, Dickinson and Co., Franklin Lakes, NJ, USA) to separate the upper and lower chambers. THP-1 cells were cultured in the upper chamber at $2 \times 10^{5}$ cells $/ \mathrm{ml}$, and adipocytes were cultured in the lower chamber at $2 \times 10^{5}$ cells $/ \mathrm{ml}$. THP- 1 cells and adipocytes were collected on day 5 after the initiation of co-culture.

\section{RNA Extraction}

Total RNA from THP-1 cells and adipocytes was extracted using TRIzol ${ }^{\circledR}$ Reagent (Invitrogen Corporation, Carlsbad, CA, USA), according to the manufacturer's protocol. RNA was quantified by absorbance at $260 \mathrm{~nm}$. cDNA was synthesized using reverse transcriptase with Oligo(dT)20 (TOYOBO Co, Ltd., Osaka, Japan).

\section{Quantitative Real-Time PCR}

Real-time PCR was performed using SsoFast ${ }^{\mathrm{TM}}$ EvaGreen ${ }^{\circledR}$ Supermix (Bio-Rad Laboratories, Inc. Hercules, CA, USA) on a MiniOpticon (Bio-Rad Laboratories, Inc.). The primers used have been previously described [26]. PCR conditions were set at $95^{\circ} \mathrm{C}$ for $3 \mathrm{~min}$, followed by 40 cycles of $95^{\circ} \mathrm{C}$ for $10 \mathrm{~s}$ and $60^{\circ} \mathrm{C}$ for $30 \mathrm{~s}$. Relative quantification was performed by normalizing target expression to the housekeeping gene $\beta$-actin. Data are expressed as change (n-fold) in mRNA expression compared with that of THP1 cells incubated without LPS or adipocytes before co-culture.

\section{DNA Microarray}

The gene expression in LPS-pretreated $(10 \mathrm{ng} / \mathrm{ml})$ THP-1 cells and adipocytes on day 5 of co-culture was analyzed using the fibrous DNA microarray Genopal ${ }^{\circledR}$ (Mitsubishi Rayon, Tokyo, Japan). Genopal ${ }^{\circledR}$, which consists of gel-filled plastic fibers, has high reproducibility and high sensitivity [27]. DNA oligonucleotide probes were used to detect for 208 genes related to lipid and sugar metabolism. Data are expressed as change ( $n$-fold) in gene expression compared with that of THP-1 cells or adipocytes before co-culture.

\section{Statistical Analysis}

Data from the four experiments are presented as mean \pm standard deviation. Data analysis was performed using a twotailed Student's $t$ test. Statistical significance between groups was considered at $P<0.05$.

\section{Results}

\section{mRNA Expression in Adipocytes}

We investigated changes in the mRNA expression of inflammatory factor $I L-1 \beta$ and chemotactic factor $M C P-1$ in adipocytes on day 5 of co-culture. The mRNA expression of $I L-1 \beta$ and $M C P-1$ in adipocytes increased following co-culture with THP-1 cells. The increased mRNA expression of $I L-1 \beta$ in adipocytes after co-culture was suppressed by $31.1 \%$ and $26.7 \%$ following interaction with THP- 1 cells pretreated with $10 \mathrm{ng} / \mathrm{ml}$ and $1 \mu \mathrm{g} / \mathrm{ml}$ LPS, respectively $(P=0.001, P=0.007)$ (Figure 1$)$. The increased mRNA expression of $M C P-1$ in adipocytes after co-culture was slightly suppressed by $5.9 \%$ and $9.6 \%$ following interaction with THP-1 cells pretreated with $10 \mathrm{ng} / \mathrm{ml}$ and $1 \mu \mathrm{g} / \mathrm{ml}$ LPS, respectively (Figure 1).

Plasma levels of adiponectin were known to be reduced in obese patients [28]. Therefore, we investigated changes in the mRNA expression of adiponectin in adipocytes on day 5 of co-culture. The mRNA expression of adiponectin in adipocytes decreased following co-culture with THP-1 cells. The decreased mRNA expression of adiponectin in adipocytes after co-culture increased by $15.1 \%$ following interaction with THP-1 cells pretreated with $100 \mathrm{pg} / \mathrm{ml}$ LPS (Figure 1). These results suggested that the mRNA expression of inflammatory factor and chemotactic factor in adipocytes after co-culture is regulated by LPS-pretreated monocytes and that an increase in mRNA expression of adiponectin is due to the antiinflammatory effect of low-dose LPS-pretreated monocytes. 

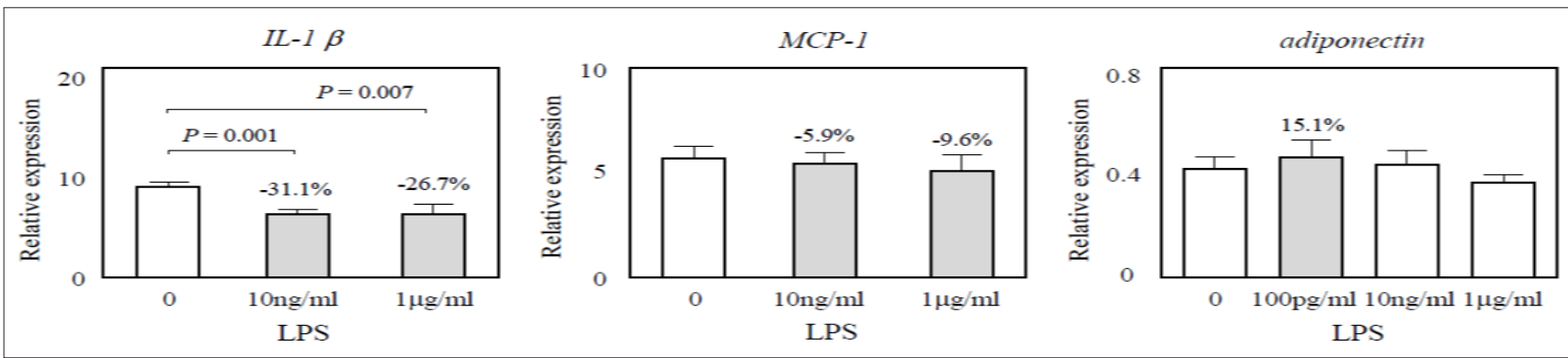

Figure 1: mRNA expression in adipocytes. The mRNA expression of $I L-1 \beta, M C P-1$, and adiponectin in adipocytes on day 5 of co-culture with LPS-pretreated THP-1 cells was analyzed using quantitative real-time PCR. Relative quantification was performed by normalization to the value of the housekeeping gene $\beta$-actin. Data are expressed as change (n-fold) in mRNA expression compared with that of adipocytes before co-culture.

\section{mRNA Expression in Monocytes}

We investigated changes in the mRNA expression of inflammatory factor $I L-1 \beta$ and chemotactic factor $M C P-1$ in THP-1 cells on day 5 of co-culture. The mRNA expression of $I L-1$ $\beta$ and $M C P-1$ in THP-1 cells increased following co-culture with adipocytes. The increased mRNA expression of $I L-1 \beta$ in THP- 1 cells after co-culture was slightly suppressed by $6.4 \%$ and $6.0 \%$ with LPS pretreatment of $10 \mathrm{ng} / \mathrm{ml}$ and $1 \mu \mathrm{g} / \mathrm{ml}$, respectively (Figure 2). In addition, the increased mRNA expression of MCP-1 in THP-1 cells after co-culture was significantly suppressed by $63.2 \%$ and $63.0 \%$ with LPS pretreatment of $10 \mathrm{ng} / \mathrm{ml}$ and $1 \mu \mathrm{g} / \mathrm{ml}$, respectively $(P=$ $0.0017, P=0.0018$ ) (Figure 2). These results suggested that the mRNA expression of chemotactic factor in THP-1 cells after coculture is more strongly regulated by LPS-pretreatment than that in adipocytes.

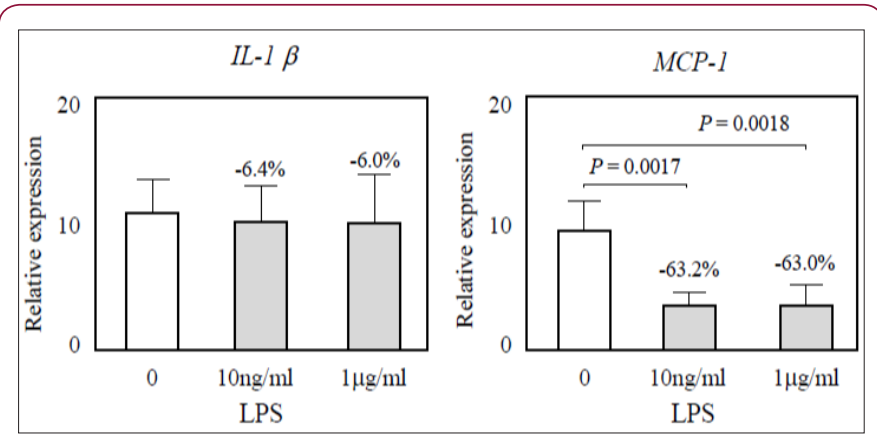

Figure 2: mRNA expression in monocytes. The mRNA expression of $I L-1 \quad \beta$ and $M C P-1$ in LPS-pretreated THP-1 cells on day 5 of co-culture with adipocytes was analyzed using quantitative real-time PCR. Relative quantification was performed by normalization to the value of the house keeping gene $\beta$-actin. Data are expressed as change (n-fold) in mRNA expression compared with that of THP1 cells incubated without LPS before co-culture.

\section{mRNA Expressions Using a Fibrous DNA microarray}

We investigated changes in the expression of 208 genes in adipocytes and THP- 1 cells on day 5 of co-culture using a semiquantitative fibrous DNA microarray. It was demonstrated that the increased mRNA expression of CD14, CCL5, and CD86 in adipocytes was suppressed by $37.7 \%, 16.3 \%$, and $68.4 \%$, respectively, following interaction with LPS-pretreated (10ng/ml) THP-1 cells (Figure 3).
In addition, the increased mRNA expression of CD14 and IFNA5 in THP-1 cells after co-culture with adipocytes was demonstrated to be suppressed by $14.2 \%$ and $12.0 \%$ with the LPS pretreatment of $10 \mathrm{ng} / \mathrm{ml}$, respectively (Figure 4).

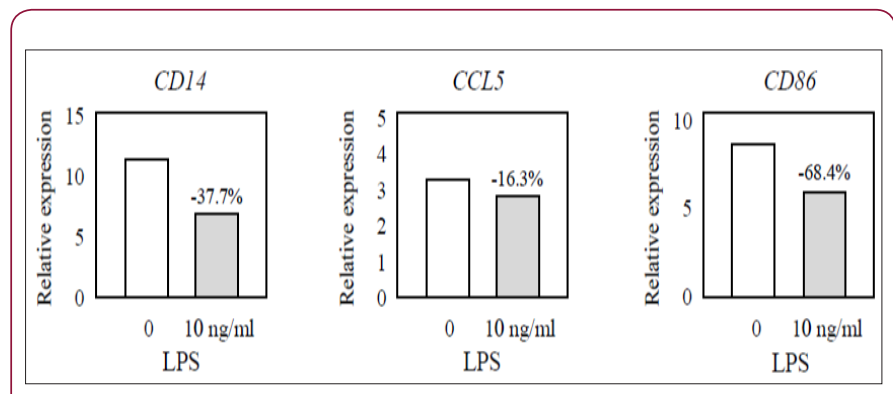

Figure 3: Gene expression in adipocytes using a DNA microarray. Gene expression in adipocytes was analyzed using a DNA microarray on day 5 of co-culture with LPSpretreated $(10 \mathrm{ng} / \mathrm{ml})$ THP-1 cells. Data are expressed as change (n-fold) in gene expression compared with that of adipocytes before co-culture.

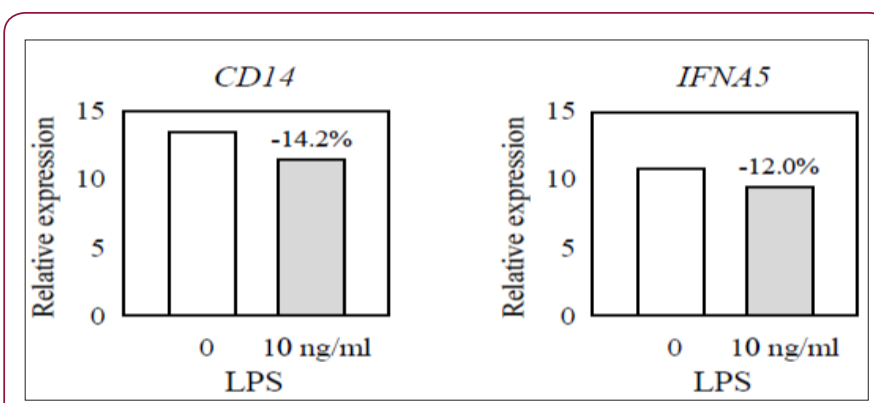

Figure 4: Gene expression in monocytes using a DNA microarray. Gene expression in LPS-pretreated (10 ng/ $\mathrm{ml}$ ) THP-1 cells was analyzed using a DNA microarray on day 5 of co-culture with adipocytes. Data are expressed as change (n-fold) in gene expression compared with that of without LPS treatment before co-culture.

\section{Discussion}

Our previous reports have demonstrated that the increased mRNA expression of inflammatory factors, $I L-1 \beta, I L-8, V E G F-A$, TNF- $\alpha$, in human monocytes by humoral factor-mediated interactions with cancer cells was suppressed by low-dose 
LPS pretreatment. These results suggested that low-dose LPS-pretreated human monocytes regulate the production of inflammatory cytokines in tumor tissues [16-18]. In this study, we demonstrated that the increased mRNA expression of the inflammatory factor $I L-1 \beta$ in human adipocytes was significantly suppressed by interaction with LPS-pretreated human monocytes (Figure 1). In addition, the decreased mRNA expression of the anti-inflammatory factor adiponectin in human adipocytes was increased by interaction with LPS-pretreated human monocytes (Figure 1). These results suggested that LPS-pretreated human monocytes may have anti-inflammatory effect in adipose tissues as well as tumor tissues. Therefore, LPS-treated human monocytes may regulate inflammatory reactions. It has been shown that inflammatory changes observed in adipose tissues with visceral obesity contribute to the development of metabolic syndrome [1922]. Suppressing expression of inflammatory factor using LPS may thus help to prevent the occurrence of metabolic syndrome.

It was reported that the chemotactic factor MCP-1 increased in adipose tissues with obesity and that infiltration of macrophages into adipose tissues was performed via the MCP-1 receptor; C-C chemokine receptor-2 [29-31]. MCP-1 has been shown to play an important role in the accumulation of macrophages in adipose tissues with obesity. Our data indicated that the mRNA expression of $M C P-1$ in human adipocytes increased spontaneously by interactions with human monocytes, and that this increase was slightly suppressed by interaction with LPS-pretreated human monocytes. In addition, the increased mRNA expression of MCP-1 in human monocytes by interaction with human adipocytes was significantly suppressed by LPS-pretreatment. The regulation of expression of MCP-1 by LPS may inhibit infiltration of macrophages and subsequently decrease accumulation of macrophages in adipose tissues.

Recent reports have shown that macrophages infiltrated the arterial wall and form foam cells, and that they induce inflammatory changes in tissues by secreting inflammatory cytokines [9-11]. It has been suggested that chronic inflammation in obesity affects the occurrence of diabetes $[12,13]$. The regulation of MCP-1 expression by LPS may help to prevent the occurrence of diabetes. Thus, LPStreated human monocytes may be beneficial for the prevention of diseases caused by chronic inflammation.

DNA microarray analysis findings demonstrated that the increased mRNA expressions of CD14, CCL5, and CD86 in human adipocytes were suppressed by interaction with LPS $(10 \mathrm{ng} / \mathrm{ml})$ pretreated human monocytes. Also, it was demonstrated that the increased mRNA expressions of CD14 and IFNA5 in human monocytes following interaction with human adipocytes were demonstrated to be suppressed by LPS $(10 \mathrm{ng} / \mathrm{ml})$ pretreatment. CD14 is known to be a receptor of LPS. The molecular responses of human monocytes following interaction with human adipocytes may be tolerated by LPS-pretreatment. As previously reported, DNA microarray analysis findings demonstrated that the increased mRNA expression of CD86 in human monocytes following interaction with hepatic cancer cells was suppressed by LPS-pretreatment [18].
CD86, a T-cell co-stimulatory molecule, was shown to contribute to T-cell suppression [32]. Therefore, it is suggested that LPS-treated human monocytes regulate inflammation response through T-cell regulation in adipose tissues as well as tumor tissues.

\section{References}

1. Burke B, Lewis CE (2002) The macrophage. Oxford University Press, Oxford, New York.

2. Wynn TA, Chawla A, Pollard JW (2013) Macrophage biology in development, homeostasis and disease. Nature 496(7446): 445-455.

3. Gordon S, Taylor PR (2005) Monocyte and macrophage heterogeneity. Nat Rev Immunol 5(12): 953-964.

4. Bingle L, Brown NJ, Lewis CE (2002) The role of tumour-associated macrophages in tumour progression: implications for new anticancer therapies. J Pathol 196(3): 254-265.

5. Pollard JW (2004) Tumour-educated macrophages promote tumour progression and metastasis. Nat Rev Cancer 4(1): 71-78.

6. Qian BZ, Pollard JW (2010) Macrophage diversity enhances tumor progression and metastasis. Cell 141(1): 39-51.

7. Condeelis J and Pollard JW (2006) Macrophages: Obligate partners for tumor cell migration, invasion and metastasis. Cell 124(2): 263-266.

8. Brown MS, Goldstein JL (1983) Lipoprotein metabolism in the macrophage: implications for cholesterol deposition in atherosclerosis. Annu Rev Biochem 52: 223-261.

9. Wellen KE, Hotamisligil GS (2003) Obesity-induced inflammatory changes in adipose tissue. J Clin Invest 112(12): 1785-1788.

10. Cinti S, Mitchell G, Barbatelli G, Murano I, Ceresi E, et al. (2005) Adipocyte death defines macrophage localization and function in adipose tissue of obese mice and humans. J Lipid Res 46(11): 2347-2355.

11. Weisberg SP, McCann D, Desai M, Rosenbaum M, Leibel RL, et al. (2003) Obesity is associated with macrophage accumulation in adipose tissue. J Clin Invest 112(12): 1796-1808.

12. Xu H, Barnes GT, Yang Q Tan G, Yang D, et al. (2003) Chronic inflammation in fat plays a crucial role in the development of obesity-related insulin resistance. J Clin Invest 112(12): 1821-1830.

13. Jose MF, Wifredo R (2003) Insulin Resistance and Chronic Cardiovascular Inflammatory Syndrome. Endocrine Reviews 24(3): 278-301.

14. Opal SM, Scannon PJ, Vincent JL, White M, Carroll SF, et al. (1999) Relationship between plasma levels of lipopolysaccharide (LPS) and LPS-binding protein in patients with severe sepsis and septic shock. J Infect Dis 180(5): 1584-1589.

15. Braun-Fahrländer C, Riedler J, Herz U, Eder W, Waser M, et al. (2002) Environmental exposure to endotoxin and its relation to asthma in school-age children. N Engl J Med 347(12): 869-877.

16. Honda T, Inagawa H, Yamamoto I (2014) Expression of chemotaxis- and angiogenesis-related factors in human monocytes following interaction with colon cancer cells is suppressed by low-dose lipopolysaccharide. Anticancer Res 34(8): 4609-4613.

17. Honda T, Inagawa H (2015) Molecular response of human monocytes following interaction with colon cancer cells by pretreatment with lowdose lipopolysaccharide. Anticancer Res 35(8): 4473-4478.

18. Honda T, Inagawa H (2016) Gene expression in lipopolysaccharidetreated human monocytes following interaction with hepatic cancer cells. Anticancer Res 36(7): 3699-3704.

19. Hotamisligil GS (2006) Inflammation and metabolic disorders. Nature 444(7121): 860-867.

20. Berg AH, Scherer PE (2005) Adipose tissue, inflammation, and cardiovascular disease. Circ Res 96(9): 939-949. 
21. Rocha VZ, Libby P (2009) Obesity, inflammation, and atherosclerosis Nat Rev Cardiol 6(6): 399-409.

22. Matsuzawa Y, Funahashi T, Nakamura T (1999) Molecular mechanism of metabolic syndrome $\mathrm{X}$ : contribution of adipocytokines adipocytederived bioactive substances. Ann N Y Acad Sci 892: 146-154.

23. Kohchi C, Inagawa H, Nishizawa T, Yamaguchi T, Nagai S, et al. (2006) Applications of lipopolysaccharide derived from Pantoea agglomerans (IP-PA1) for health care based on macrophage network theory. J Biosci Bioeng 102(6): 485-496.

24. Inagawa H, Kohchi C, Soma G (2011) Oral administration of lipopolysaccharides for the prevention of various diseases: benefit and usefulness. Anticancer Res 31(7): 2431-2436.

25. Kobayashi Y, Inagawa H, Kohchi C, Kazumura K, Tsuchiya H, et al. (2018) Oral administration of Pantoea agglomerans-derived lipopolysaccharide prevents development of atherosclerosis in high-fat diet-fed apoEdeficient mice via ameliorating hyperlipidemia, pro-inflammatory mediators and oxidative responses. PLoS One 13(3): e0195008

26. Honda T, Yamamoto I, Inagawa H (2013) Angiogenesis-, metastasis- and signaling pathway-related factor dynamics in human colon cancer cells following interaction with monocytes. Anticancer Res 33(7): 2895-2900.

27. Okuzaki D, Fukushima T, Tougan T, Ishii T, Kobayashi S, et al. (2010) Genopal $^{\mathrm{TM}}$ : a novel hollow fibre array for focused microarray analysis.

\section{ISSN: 2574-1241}

DOI: 10.26717/BJSTR.2018.07.001522

Teruko Honda. Biomed J Sci \& Tech Res

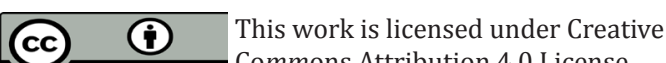

Submission Link: https://biomedres.us/submit-manuscript.php
DNA Res 17(6):369-379.

28. Okamoto Y, Kihara S, Funahashi T, Matsuzawa Y, Libby P (2006) Adiponectin: a key adipocytokine in metabolic syndrome. Clin Sci $110(3): 267-278$

29. Kanda H, Tateya S, Tamori Y, Kotani K, Hiasa K, et al. (2006) MCP-1 contributes to macrophage infiltration into adipose tissue, insulin resistance, and hepatic steatosis in obesity. J Clin Invest 116(6): 14941505.

30. Kamei N, Tobe K, Suzuki R, Ohsugi M, Watanabe T, et al. (2006) Overexpression of monocyte chemoattractant protein-1 in adipose tissues causes macrophage recruitment and insulin resistance. J Biol Chem 281(36): 26602-26614.

31. Ito A, Suganami T, Yamauchi A, Degawa Yamauchi M, Tanaka M, et al. (2008) Role of CC chemokine receptor 2 in bone marrow cells in the recruitment of macrophages into obese adipose tissue. J Biol Chem 283(51): 35715-35723.

32. Walker LS, Sansom DM (2015) Confusing signals: recent progress in CTLA-4 biology. Trends Immunol 36(2):63-70.

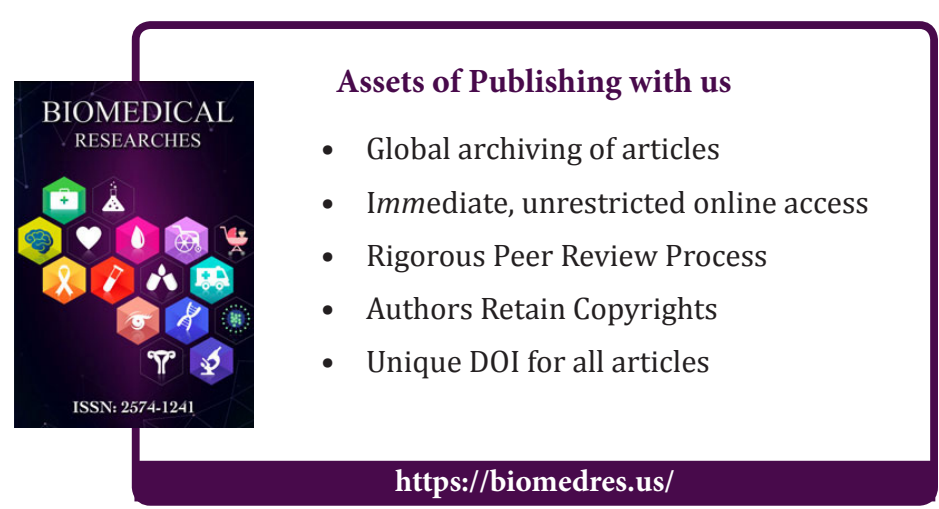

